\title{
Cell-Mediated Immunity after Bacterial Infection of the Lower Respiratory Tract
}

\author{
J. Robert CANTEy and W. Lee HAND, with the technical assistance of \\ Carl G. Hughes, Mary E. Lund, and Neva L. King \\ From the Veterans Administration Hospital (Atlanta), Decatur, Georgia 30033, \\ and the Department of Medicine, Emory University School of Medicine, \\ Atlanta, Georgia 30303
}

\begin{abstract}
A в S T R A T Lower respiratory tract and systemic cell-mediated immunity have been studied in rabbits after infection with Listeria monocytogenes or Diplococcus pneumoniae. Respiratory tract cell-mediated immunity was evaluated by direct and indirect assays of migration inhibitory factor (MIF) production. Systemic delayed hypersensitivity was determined by means of intradermal testing with appropriate antigens.

Aerosol exposure to listeria was followed by markedly increased numbers of free lower respiratory tract cells. These cells manifested antigen-stimulated inhibition of migration (mean inhibition of migration $=$ $30.4 \%$ ). Pneumococcal pneumonia was associated with similar but less dramatic changes. Intravenous administration of organisms was uncommonly followed by inhibition of lower respiratory tract cells in direct migration assays.

Fractionated MIF, as well as crude supernates of antigen-stimulated lower respiratory tract and lymph node lymphocytes from animals exposed to listeria aerosols, caused inhibition of normal alveolar macrophage migration. MIF, produced by lymph node lymphocytes, has a molecular weight of approximately 65,000 and is inactivated by chymotrypsin or neuraminidase.

Delayed dermal hypersensitivity to listeria antigen was observed in 54 of 55 animals exposed to listeria aerosols and in all 9 animals infected by the intravenous route. Delayed dermal reactions to pneumococcal sonicate antigen (but not capsular polysaccharide) followed $D$. pneumoniae respiratory tract infection in 19 of 28 animals, and was elicited in 5 of 6 animals after intravenous infection.
\end{abstract}

Dr. Hand is a Clinical Investigator, Veterans Administration Hospital (Atlanta).

Received for publication 15 March 1974 and in revised form 22 July 1974.
Both local (macrophage migration inhibition) and systemic delayed hypersensitivity followed bacterial infection of the lower respiratory tract. MIF activity was shown to be one mechanism for inhibition of alveolar macrophage migration.

\section{INTRODUCTION}

Specific lower respiratory tract (LRT) ${ }^{1}$ immune mechanisms which might contribute to antibacterial activity are incompletely defined. Local synthesis and secretion of specific antibody occur after infection of the LRT with either Listeria monocytogenes or Diplococcus pneumoniae (1). The role of local and systemic cellmediated immunity $(\mathrm{CMI})^{2}$ after bacterial infection of the LRT has not been evaluated. Local CMI, assayed by the technique of macrophage migration inhibition, has been demonstrated after stimulation of the respiratory tract with various antigens, including mycobacteria and inactivated influenza virus $(2-8)$. It was assumed that alveolar macrophage migration inhibition was secondary to release of macrophage migration inhibitory factor (MIF) by sensitized lymphocytes in the presence of antigen. However, Leu, Eddleston, Hadden, and Good reported that MIF had no effect on guinea pig alveolar macrophages (9), thus questioning the mechanism of alveolar macrophage migration inhibition noted in the aforementioned studies.

The study to be reported was designed to evaluate both LRT and systemic CMI after the introduction of

${ }^{1}$ Abbreviations used in this paper: CMI, cell-mediated immunity; LRT, lower respiratory tract; MIF, migration inhibitory factor; NRS, pooled normal rabbit serum; PBS, phosphate-buffered saline; TC 199, tissue culture medium 199 containing penicillin and streptomycin.

2 The terms "cell-mediated immunity" and "delayed hypersensitivity" will be used interchangeably. 
virulent bacteria into the LRT or systemic circulation of rabbits. The two infecting organisms (D. pneumoniae and L. monocytogenes) have contrasting characteristics and were chosen so that an enhanced view of CMI after bacterial infection could be obtained. In addition, rabbit MIF has been partially characterized and was shown to inhibit the migration of alveolar macrophages.

\section{METHODS}

\section{Bacteria}

Recent clinical isolates of Listeria monocytogenes and Diplococcus pneumoniae type III were stored frozen $\left(-70^{\circ} \mathrm{C}\right)$. Virulence of the pneumococcal strain was maintained by serial passage in mice. For the studies to be described, listeria were grown overnight in trypticase soy broth (BBL, Division of Becton, Dickinson, and Co., Cockeysville, Md.) and pneumococci were similarly cultured in brain heart infusion (Difco Laboratories, Detroit, Mich.) containing $15 \%$ normal sheep serum (Miles Laboratories, Inc., Miles Research Div., Kankakee, III.).

\section{LRT infection}

As previously described, infection with Listeria monocytogenes was produced in 5-6-1b New Zealand male rabbits by exposure in an aerosol apparatus (Tri-R Airborne Infection Apparatus, Tri-R Instruments, Inc., Rockville Centre, N. Y.) (1). In early experiments, Diplococcus pneumoniae infection was initiated by aerosolization or by percutaneous intratracheal injection of organisms. Since true pneumococcal consolidation was not produced by the above techniques, infection in later experiments was initiated by intratracheal or intrabronchial inoculation of $2 \times 10^{5}-1 \times 10^{\circ}$ organisms in 5\% mucin. Animals were anesthetized with sodium thiopental, and the pneumococci-mucin mixture was introduced either by a rubber catheter inserted through the oropharynx into the distal trachea or main stem bronchus, or through a 21-gauge needle inserted into the trachea by percutaneous puncture.

Illness was characterized by fever, weight loss, lethargy, and labored respirations. Animals were treated with antibiotics just before study to eradicate infecting organisms that might remain. In a few animals, antibiotic therapy was required by the 4 th or 5 th day after infection because of overwhelming illness. Rabbits infected with listeria received $50 \mathrm{mg} / \mathrm{kg} /$ day of ampicillin (Bristol Laboratories, Div., Bristol-Myers Co., Syracuse, N. Y.) and animals infected with pneumococci were given $25 \mathrm{mg} / \mathrm{kg} / \mathrm{day}$ of penicillin (The Upjohn Company, Kalamazoo, Mich.).

\section{Systemic infection}

L. monocytogenes $\left(1 \times 10^{7}\right.$ organisms) or $D$. pneumoniae type III $\left(1 \times 10^{8}\right.$ organisms $)$ were given in the lateral ear vein of rabbits. Illness in these animals was manifested as fever, weight loss, and somnolence.

\section{Bacterial antigens}

$L$. monocytogenes and $D$. pneumoniae were grown overnight (as described above), washed, and resuspended in phosphate-buffered saline (PBS). The cells were disrupted in an ultrasonic apparatus (Lab-Line Ultratip Labsonic
System, Lab-Line Instruments, Inc., Melrose Park, Ill.). After centrifugation, the supernates were dialyzed against PBS, sterilized by membrane filtration, and stored at $-20^{\circ} \mathrm{C}$. Protein content of these preparations was determined by the method of Lowry, Rosebrough, Farr, and Randall (10).

$D$. pneumoniae type III polysaccharide was prepared by alcohol precipitation from culture supernate, followed by extensive extraction with chloroform-butanol (11).

\section{Intradermal testing procedures}

Systemic CMI was evaluated by intradermal testing of both normal and infected animals. $0.1 \mathrm{ml}$ of the appropriate antigen was injected intradermally in the shaved flank of the rabbits. Based upon preliminary evaluation, the following antigen dosages were administered: L. monocytogenes sonicate antigen, $35 \mu \mathrm{g}$ of protein; $D$. pneumoniae sonicate antigen, $25 \mu \mathrm{g}$ of protein; D. pneumoniae polysaccharide, $100 \mu \mathrm{g}$ (dry weight). Skin tests were evaluated at 4, 24, and $48 \mathrm{~h}$. Delayed induration with a diameter $\geq 10 \mathrm{~mm}$ at $24 \mathrm{~h}$ was considered a positive test. To confirm that positive dermal reactions represented delayed hypersensitivity, a number of skin tests were biopsied.

Normal and infected animals were anesthetized with sodium thiopental and sacrificed by exsanguination. By a previously described technique $(1,12)$, the LRT was lavaged with a total of $300 \mathrm{ml}$ of calcium- and magnesiumfree Hanks' solution (Grand Island Biological Co., Grand Island, N. Y.) containing $10 \mathrm{U} / \mathrm{ml}$ heparin (Schwarz/Mann Div., Becton, Dickinson \& Co., Orangeburg, N. Y.), 100 $\mathrm{U} / \mathrm{ml}$ penicillin, and $100 \mu \mathrm{g} / \mathrm{ml}$ streptomycin (Difco Laboratories). LRT cells were recovered by centrifugation, washed twice in tissue culture medium 199 (BBL) containing $100 \mathrm{U} / \mathrm{ml}$ penicillin, and $100 \mu \mathrm{g} / \mathrm{ml}$ streptomycin (TC 199), and used in the procedures described below. After lavage, lung tissue was excised and placed in formaldehyde for histological examination. Thoracic, axillary, and anterior cervical lymph nodes from a group of animals exposed to listeria aerosols were aseptically removed for use in studies of antigen-stimulated MIF.

\section{Enumeration and identification of cells from the LRT}

The volume of the cell button after centrifugation was noted, and the cells were then resuspended and counted in a hemocytometer. Cell viability was determined by the trypan blue exclusion technique. Papanicolaou-stained preparations were used for differential counting.

\section{Direct and indirect assays for inhibition of} alveolar macrophage migration

Direct assay $(13,14)$. LRT cells were made up to $10 \%$ by volume in TC 199 with $15 \%$ inactivated, pooled, normal rabbit serum (NRS) (Research Products Division, Miles Laboratories) and placed in $80-\mu 1$ capillary tubes, which were centrifuged and cut at the cell-supernate interface. The cell-containing capillary segments were placed in SykesMoore chambers (Bellco Glass, Inc., Vineland, N. J.), which were filled with TC 199-15\% NRS, with or without the appropriate bacterial antigen ( $L$. monocytogenes sonicate antigen, $60 \mu \mathrm{g}$ protein $/ \mathrm{ml} ; D$. pneumoniae sonicate antigen, $50 \mu \mathrm{g}$ protein $/ \mathrm{ml}$; and $D$. pneumoniae polysaccharide, $100 \mu \mathrm{g} / \mathrm{ml}$ ). LRT cells from normal animals, with and without antigen, were included in each experiment as a 
control for antigen toxicity. The chambers were incubated at $37^{\circ} \mathrm{C}$ in $95 \%$ air $-5 \% \mathrm{CO}_{2}$. The migration of cells from the capillaries was measured at 24 and $48 \mathrm{~h}$, and expressed as percent inhibition of migration: $\%$ inhibition $=100-$ (average migration of cells with antigen/average migration of cells without antigen) $\times 100$. Migration inhibition of at least $20 \%$ was considered to be significant.

Indirect assay $(15,16)$. Lymph node cells (lymphocytes) from animals with listeria LRT infection were obtained by teasing the nodes on stainless steel sieves (containing 100 mesh stainless steel cloth) (W. S. Tyler, Inc. Mentor, Ohio). Cells were washed twice in TC 199 without serum, and diluted to a concentration of $5 \times 10^{6}-2 \times 10^{7}$ viable cells $/ \mathrm{ml}$ in the same medium. Sets of culture tubes containing $1.5 \mathrm{ml}$ of cells per tube were set up with and without L. monocytogenes antigen $(60 \mu \mathrm{g}$ protein $/ \mathrm{ml})$. Control tubes for antigen toxicity, containing medium or medium plus antigen (but no cells), were prepared and carried through the steps listed below. All tubes were incubated for $24 \mathrm{~h}$ at $37^{\circ} \mathrm{C}$ in $95 \%$ air- $5 \% \mathrm{CO}_{2}$. After incubation, cells were removed by centrifugation, and the supernates were passed through $0.22-\mu \mathrm{m}$ filters (Millipore Corp., Bedford, Mass.). After the addition of $15 \%$ inactivated NRS, the supernates were added to Sykes-Moore chambers with capillaries of normal LRT cells. Incubation was as described for the direct assay. The percent of macrophage migration inhibition was calculated as follows:

$\%$ inhibition

$$
=100-\left(\begin{array}{c}
\text { (area of migration in supernate with antigen/ } \\
\text { area of migration in media with antigen) } \\
\begin{array}{c}
\text { (area of migration in supernate without antigen/ } / \\
\text { area of migration in media without antigen })
\end{array}
\end{array} \times 100\right)
$$

LRT lymphocytes from normal or listeria-infected animals were partially purified by removal of adherent LRT cells (macrophages) on plastic petri dishes. After incubation for $1 \mathrm{~h}$ at $37^{\circ} \mathrm{C}$ in $95 \%$ air $-5 \% \quad \mathrm{CO}_{2}$, nonadherent cells were washed off the plates with TC 199 , and then replated in the same manner. Lymphocytes represented approximately $50 \%$ of the nonadherent cell population after three platings. These cells were adjusted to a concentration of $1-4 \times 10^{6}$ lymphocytes $/ \mathrm{ml}$, and incubated as described above for lymph node cells. Macrophage migration inhibitory activity of the supernates was assayed on normal LRT cells.

\section{Properties of antigen-stimulated MIF}

Cells from thoracic, axillary, and anterior cervical lymph nodes of animals infected by aerosol administration of $L$. monocytogenes were incubated (at a concentration of $2 \times$ $10^{z}$ viable cells $/ \mathrm{ml}$, with or without antigen) as described in the preceding section. After incubation, listeria antigen $(60 \mu \mathrm{g}$ protein $/ \mathrm{ml})$ was added to the control supernates. The supernates were dialyzed in the cold against saline, and then against deionized water, before lyophilization. $150 \mathrm{ml}$ of supernates from listeria antigen-stimulated incubations (stimulated supernates) and an equal volume of supernates from incubations without antigen (control supernates) were processed in this manner and reconstituted in $3 \mathrm{ml}$ of PBS. The reconstituted supernates were fractioned on a calibrated $2.5 \times 90-\mathrm{cm}$ column of Sephadex G-75 (Pharmacia Fine Chemicals, Inc., Piscataway, N. J.) at a constant flow rate of $10 \mathrm{ml} / \mathrm{h}$ against gravity. 5-ml fractions were collected by an LKB fraction collector (LKB-Produkter, A.B., Stockholm, Sweden). The large, excluded protein peak was designated fraction $\mathrm{A}$, and subsequent consecutive $25-\mathrm{ml}$ volumes were pooled and designated as fractions $B, C, D$, etc. Fractions were concentrated, reconstituted in TC 199 with $15 \% \mathrm{NRS}$, and added to Sykes-Moore chambers containing capillaries of normal alveolar macrophages. The final volumes of stimulated and control fractions in the assay chambers were concentrated five times, as compared to the original supernate volumes (17).

Unfractionated supernates, as well as the Sephadex G-75 fractionated material, were evaluated by immunoelectrophoresis and double diffusion in agar against goat antirabbit serum (Research Products Division, Miles Laboratories), goat anti-rabbit IgG, and goat anti-rabbit IgM (1). Unfractionated supernates and fractions containing MIF activity, as well as the corresponding control preparations, were incubated with insolubilized chymotrypsin (Research Products Division, Miles Laboratories) and neuraminidase $(0.57 \mathrm{U} / \mathrm{mg}$ ) (Worthington Biochemical Corp., Freehold, N. J.) as previously described $(18,19)$. These treated preparations were assayed for macrophage migration inhibitory activity in the manner described above.

\section{Histology}

Skin biopsies and lung tissue were fixed in formaldehyde, embedded in paraffin, sectioned, and stained with hematoxylin and eosin.

\section{RESULTS}

\section{Histology}

As previously reported, animals infected with $L$. monocytogenes by the aerosol route develop bronchopneumonia, with formation of microabscesses and granulomatous lesions. In two of nine animals receiving intravenous $L$. monocytogenes, residual microabscesses were found in the lungs at sacrifice. $D$. pneumoniae III administered by aerosol or intratracheal injection usually produces mild bronchopneumonia, with occasional empyema or purulent pericarditis. Intratracheal or intrabronchial injection of $D$. pneumoniae-mucin reliably caused lobar pneumonia. Intravenous injection of pneumococci produced no obvious lung lesions.

\section{Enumeration and identification of cells from} the LRT ( Table I)

Respiratory tract lavage in normal animals yielded $43.8 \pm 2.6 \times 10^{\circ}$ cells (mean \pm SEM). The number of LRT cells was increased in animals infected with listeria by aerosol or by intravenous injection. Similarly, an increase in LRT cells followed pneumococcal infection initiated by intratracheal inoculation of organisms and mucin but not after LRT exposure to organisms without mucin or after intravenous administration of organisms. As shown in Table I, the differential counts of LRT cells were similar for both normal and infected animals.

Viability of cells from normal and infected animals was routinely over $95 \%$, as determined by exclusion of trypan blue. 
TABLE I

Lower Respiratory Cells from Normal and Infected Animals

\begin{tabular}{|c|c|c|c|c|c|}
\hline \multirow[b]{2}{*}{ Experimental group } & \multirow[b]{2}{*}{ Number of cells } & \multicolumn{4}{|c|}{ Differential count } \\
\hline & & Macrophages & Lymphocytes & $\begin{array}{l}\text { Polymorpho- } \\
\text { nuclear cells }\end{array}$ & $\begin{array}{l}\text { Epithelial } \\
\text { cells }\end{array}$ \\
\hline Normal & $\begin{array}{l}43.8 \pm 2.6^{*} \\
(20-80) \ddagger\end{array}$ & $\begin{array}{c}89.4 \pm 0.6 \S \\
(87-92)\end{array}$ & $\begin{array}{c}6.9 \pm 0.8 \\
(4-10)\end{array}$ & $\begin{array}{c}1.3 \pm 0.7 \\
(0-5)\end{array}$ & $\begin{array}{c}2.6 \pm 1.0 \\
(0-8)\end{array}$ \\
\hline \multicolumn{6}{|l|}{ L. monocytogenes infection } \\
\hline Aerosol & $\begin{array}{c}183.8 \pm 28.5 \| \\
(32-680)\end{array}$ & $\begin{array}{c}86.7 \pm 3.1 \\
(75-95)\end{array}$ & $\begin{array}{c}6.9 \pm 2.2 \\
(2-17)\end{array}$ & $\begin{array}{c}1.4 \pm 1.0 \\
(0-7)\end{array}$ & $\begin{array}{c}4.9 \pm 2.7 \\
(0-20)\end{array}$ \\
\hline Intravenous & $\begin{array}{l}69.8 \pm 7.99 \\
(40-100)\end{array}$ & - & - & - & - \\
\hline \multicolumn{6}{|l|}{ D. pneumoniae infection } \\
\hline Aerosol or intratracheal & $\begin{array}{c}54.5 \pm 8.9 \\
(20-100)\end{array}$ & - & - & - & - \\
\hline Intratracheal + mucin & $\begin{array}{l}80.4 \pm 7.2 \| \\
(40-120)\end{array}$ & $\begin{array}{c}88.2 \pm 4.4 \\
(69-98)\end{array}$ & $\begin{array}{c}7.8 \pm 2.7 \\
(1-17)\end{array}$ & $\begin{array}{c}2.8 \pm 2.1 \\
(0-13)\end{array}$ & $\begin{array}{c}1.0 \pm 0.4 \\
(0-2)\end{array}$ \\
\hline Intravenous & $\begin{array}{l}45.8 \pm 4.3 \\
(40-80)\end{array}$ & 一 & - & - & - \\
\hline
\end{tabular}

* Mean \pm SEM $\times 10^{6}$.

$\ddagger$ Range.

$\S$ Mean percent \pm SEM.

\| Significantly greater than normal $(P<0.001)$.

I Significantly greater than normal $(P<0.005)$.

Assays for Inhibition of Alveolar Macrophage Migration

\section{Direct assays}

In the direct assays, relative inhibition of macrophage migration was constant from 48 through at least $96 \mathrm{~h}$ (not measured later), but often was incomplete at $24 \mathrm{~h}$. Thus, 48-h migration values have been used in the following calculations.

L. monocytogenes infection. LRT cells from 9 of 12 animals exposed to listeria aerosols, and studied at intervals from 11 to 42 days after infection, exhibited at least $20 \%$ inhibition of migration in the presence of antigen (Fig. 1). Mean inhibition of migration was $30.4 \%$ ( $\mathrm{SEM} \pm 5.5 \%)$, which differs significantly from normal LRT cells $(P<0.001)$.

Animals infected by the intravenous route were sacrificed at times from 10 to 36 days (Fig. 1). Respiratory tract cells from only one animal (with obvious bilateral pulmonary lesions) were inhibited more than $20 \%$ in the migration assay.

D. pneumoniae infection. Aerosol or intratracheal administration of pneumococci to 11 animals, studied 8 to 43 days later, failed to produce inhibition of LRT cell migration in the capillary tube assay (Fig. 2). Similarly, cells from nine animals infected by the systemic route were not inhibited by pneumococcal antigen in the migration assay (10-32 days). In contrast are the results obtained with LRT cells from rabbits infected with the pneumococci-mucin mixture and studied 9-25 days after infection. Cell migrations from three of these nine animals were inhibited more than $25 \%$ in the presence of antigen. For this group, the mean inhibition of migration was $15.4 \%$ ( $\mathrm{SEM} \pm 4.0 \%$ ), a figure which is significantly different from the normal $(P<0.005)$.

While we performed the direct assays, it became apparent that the migration of LRT cells from animals with $L$. monocytogenes respiratory tract infection exceeded that of cells from normal animals in chambers without antigen. Upon analysis, it was found that those cells inhibited in the presence of antigen migrated more rapidly than normal cells in the absence of antigen. The percent of expected migration for these cells (calculated as noted below) was $152 \%$ ( $\mathrm{SEM} \pm 20.5 \%)$. $\%$ migration $=($ migration of infected cells without antigen/migration of normal cells without antigen) $\times$ 100. The number of inhibited direct migration assays using cells from animals with pneumococcal infection was inadequate for analysis.

Additional studies were performed to test the concept that the macrophage migration inhibition observed in the direct assays was due to an inhibitory material produced by lymphocytes.

Alveolar macrophages from animals exposed to listeria aerosols and studied 10 to 20 days thereafter were 
purified by adherence to plastic petri dishes for 3-4 h at $37^{\circ} \mathrm{C}$ in $95 \%$ air $-5 \% \mathrm{CO}_{2}$. Nonadherent cells were washed away with TC 199, and the macrophages were then eluted with $0.0007 \mathrm{~N}$ EDTA $(1: 5,000$ dilution in PBS) (16). Small numbers of lymphocytes $(<1 \%)$ remained with the macrophages. After being washed in TC 199, the purified macrophages were used in the migration assays. Although migrations of macrophages from two of seven animals were inhibited in the presence of listeria antigen, the mean inhibition of the group was only $8.0 \%(\mathrm{SEM} \pm 5.5 \%)$, which did not differ from the normal $(P>0.10)$.

\section{Indirect assays}

Supernates of incubated lymph node cells from five animals studied 12 to 19 days after exposure to listeria aerosols were used in indirect macrophage migration assays. Supernates from all antigen-stimulated incubations caused marked inhibition of normal LRT cell migration. In contrast to the direct assays, the inhibition of migration at $24 \mathrm{~h}(31.2 \pm 2.5 \%)$ and at $48 \mathrm{~h}(34.7$ $\pm 4.2 \%)$ in the indirect assays was similar. Supernates from antigen-stimulated incubations of lymph node cells

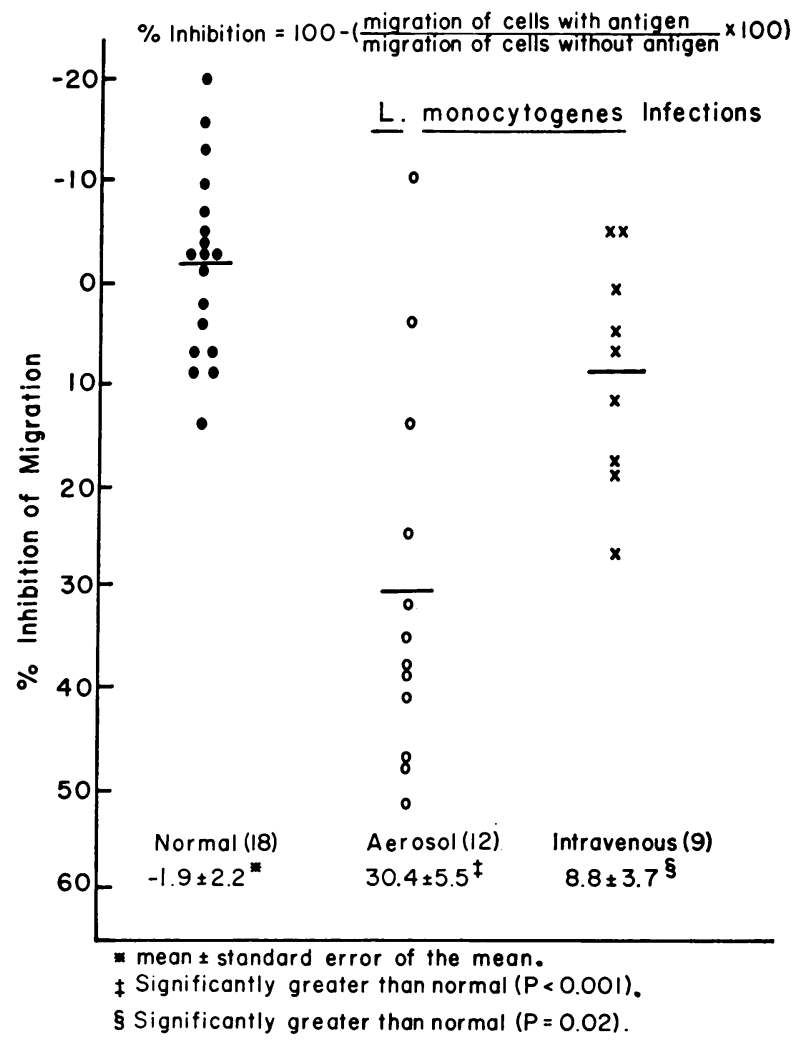

FIGURE 1 Direct capillary tube assays of LRT cell migration. The percent inhibition of migration is shown for cells from normal animals and animals infected with Listeria monocytogenes by the aerosol or intravenous route.

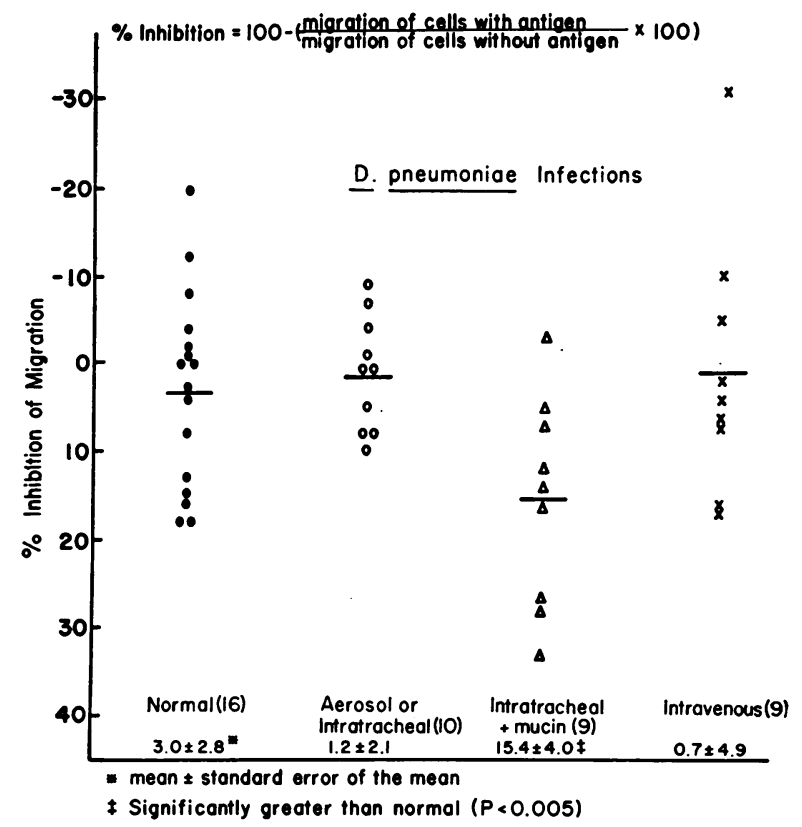

FIGURE 2 Direct capillary tube assays of LRT cell migration. The percent inhibition of migration is shown for cells from normal animals and animals infected with Diplococcus pneumoniae by the aerosol or intratracheal route, intratracheal inoculation with mucin, or intravenous administration.

from normal animals failed to inhibit the migration of normal LRT cells at $24 \mathrm{~h}(3.3 \pm 4.7 \%)$ and at $48 \mathrm{~h}$ $(-5.8 \pm 8.8 \%)$. Differences between normal and infected animals were significant at both 24 and $48 \mathrm{~h}$ $(P<0.001)$.

Supernates of antigen-stimulated LRT lymphocytes from five animals studied 8-22 days after listeria infection also produced inhibition of normal alveolar macrophage migration $(25.8 \pm 4.3 \%$ at $24 \mathrm{~h}$ and 29.8 $\pm 5.1 \%$ at $48 \mathrm{~h}$ ). With supernates of antigen-stimulated LRT lymphocytes obtained from normal animals, mean inhibition of migration was $3.0 \%( \pm 3.5 \%)$ at 24 $\mathrm{h}$ and $-5.5 \%( \pm 6.5 \%)$ at $48 \mathrm{~h}$, figures significantly different from those of the infected animals $(P<$ $0.005)$.

\section{Properties of antigen-stimulated MIF}

Stimulated and control supernates of lymph node lymphocyte incubations from sensitized animals were fractionated on Sephadex G-75 (Fig. 3). The excluded peak (fraction A) contained most of the protein, and by immunoelectrophoretic and immunodiffusion techniques was shown to include IgG and IgM. However, stimulated fraction A exhibited no inhibitory activity in the macrophage migration assays. In contrast, stimulated fraction $\mathrm{B}$, corresponding to a mol wt of approxi- 


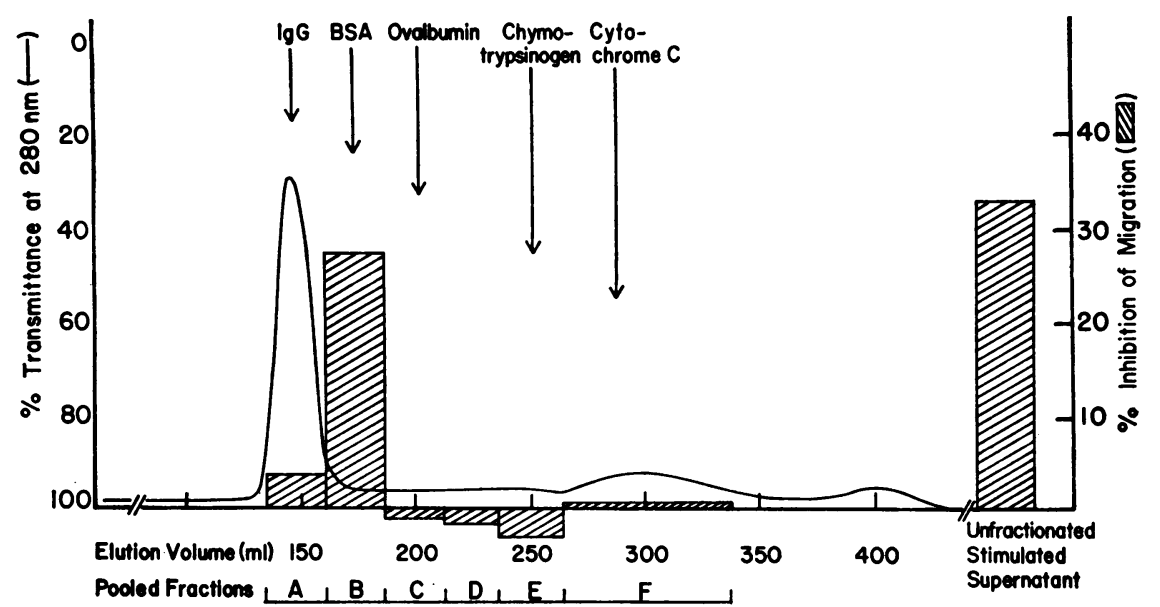

FIGURE 3 Elution of MIF activity from Sephadex G-75. Supernates of incubated lymph node cells (with or without antigen) from animals exposed to $L$. monocytogenes aerosols were dialyzed and concentrated by lyophilization before gel filtration. Elution of antigenstimulated supernate material is depicted. The column was calibrated with the indicated molecular weight markers : human IgG $(160,000)$, bovine serum albumin $(67,000)$, ovalbumin $(45,000)$, chymotrypsinogen $(25,000)$, and cytochrome $C(12,400)$. Pooled gel filtration fractions were reconstituted in tissue culture medium at concentrations five times that of the orginal supernate volumes, and assayed for MIF activity on normal LRT cells. Inhibitory activity of fractionated and unfractionated antigen-stimulated supernates is shown.

mately 65,000 , contained little protein and no demonstrable immunoglobulin, but had marked alveolar macrophage inhibitory activity $(26 \%, 31 \%$, and $24 \%$ inhibition in three separate assays). In one experiment, inhibitory activity was also present in stimulated fraction $\mathrm{D}(>25,000-45,000 \mathrm{~mol}$ wt range) at a concentration 10 times (but not 5 times) that of the original incubation volume.

Inhibitory activity of both the unfractionated stimulated supernates and stimulated fraction B was lost after overnight incubation with insolubilized chymotrypsin at room temperature. The chymotrypsin was removed by centrifugation, and absence of residual activity was verified by assay for enzyme activity. In addition, the activity of stimulated fraction $B$ was destroyed after incubation with neuraminidase at $37^{\circ} \mathrm{C}$ for $1 \mathrm{~h}$. To ensure the complete removal of neuraminidase before the migration assay, $65 \mathrm{ml}$ of stimulated and control supernates were dialyzed, concentrated, and incubated with or without neuraminidase before Sephadex G-75 filtration. On subsequent testing, fraction B (which contained no neuraminidase on assay) of the enzymatically treated stimulated supernate demonstrated no inhibitory activity (Table II).

TABLE II

Properties of MIF Produced by Antigen-Stimulated Lymph Node Cells from Animals with L. monocytogenes LRT Infection

\begin{tabular}{lccc}
\hline & \multicolumn{3}{c}{ Migration inhibitory activity* } \\
\cline { 2 - 4 } & $\begin{array}{c}\text { No enzyme } \\
\text { treatment }\end{array}$ & Enzyme treatment \\
\cline { 3 - 4 } MIF-containing preparation & 57 & -19 & ND \\
\hline $\begin{array}{c}\text { Unfractionated stimulated } \\
\text { supernate }\end{array}$ & 24 & -3 & 2 \\
$\begin{array}{c}\text { Fractionated (Sephadex G-75) } \\
\text { stimulated supernate } \\
(\text { fraction B-65,000 mol wt) }\end{array}$ & 21 & ND & $0 \S$ \\
\hline
\end{tabular}

* Assayed on normal alveolar macrophages and expressed as percent inhibition of macrophage migration.

$\ddagger$ Not done.

$\S$ Stimulated supernate was incubated with neuraminidase before gel filtration. 


\section{Intradermal testing}

L. monocytogene infections. 54 of 55 animals infected by aerosol administration of listeria exhibited delayed dermal hypersensitivity when challenged with the appropriate antigen at least 8 days after infection. Similarly, all nine animals infected by the intravenous route manifested a delayed response to the antigen. Biopsies of skin tests from three animals infected by aerosol revealed mononuclear cell infiltration compatible with delayed hypersensitivity.

D. pneumoniae infections. 19 of 28 animals tested after LRT infection manifested a delayed dermal reaction to pneumococcal sonicate antigen. However, only 1 of 13 such animals responded to pneumococcal polysaccharide. Six animals were tested after intravenous administration of organisms; five developed a delayed response to the sonicate antigen, and three, tested 9 days after incubation, revealed a mixed early and delayed response to polysaccharide. Biopsies of positive delayed skin tests in four animals with LRT infection demonstrated mononuclear cell infiltrations.

Normal animals failed to exhibit dermal response to listeria antigen (21 tested), pneumococcal sonicate antigen (14 tested) or pneumococcal polysaccharide (13 tested).

\section{DISCUSSION}

These studies represent the first comprehensive evaluation of local and systemic delayed hypersensitivity after bacterial infection of the LRT. It should be noted that we used different techniques for evaluation of local CMI (direct and indirect assays of MIF production) and systemic delayed hypersensitivity (intradermal testing). Although divergent results are occasionally obtained with these two methods (20), a number of studies have demonstrated a correlation between direct macrophage migration inhibition (or MIF production by sensitized lymphocytes) and delayed dermal hypersensitivity in response to the immunizing antigen (e.g., 13, 15, 21-25).

The infecting organisms employed in these studies differ greatly in their properties. Listeria monocytogenes is a facultative, intracellular organism, whereas the pneumococcus is a typical pyogenic extracellular bacterium. Listeria is not a common human respiratory tract pathogen, but was utilized because of its value as a model organism for the study of facultative intracellular infections. CMI, involving sensitized thymusderived lymphocytes and "activated" macrophages, is the major protection against systemic listeria infections (e.g., 26-28). Thus, as might be expected, both local and systemic delayed hypersensitivity responses were prominent after respiratory tract infection with this organism. It is perhaps more surprising that local and/or systemic delayed hypersensitivity followed introduction of Diplococcus pneumoniae into the LRT. Production of humoral antibody against type-specific capsular polysaccharide after pneumococcal infection has been well studied and is an important host defense (in association with polymorphonuclear leukocyte function) against the pneumococcus (e.g., 29). On the other hand, little is known of the delayed hypersensitivity response to this organism. Delayed dermal hypersensitivity to a protein component of $D$. pneumoniae does follow natural infection in man or immunization of animals $(30,31)$. The specific antigenic component of our pneumococcal antigen preparation which elicits delayed hypersensitivity has not been defined, but is likely to be a protein(s) since purified polysaccharide fails to stimulate this response.

Others have commented on the relative independence and separation of respiratory tract and systemic cellmediated immune responses $(2,4-6)$. After local antigenic stimulation of the respiratory tract, LRT delayed hypersensitivity developed without comparable systemic delayed hypersensitivity. However, systemic delayed hypersensitivity could be elicited by introducing larger doses of antigen or live organisms into the respiratory tract $(5,6,32,33)$. Similarly, our observations suggest that the separation of LRT and systemic delayed hypersensitivity is only a relative phenomenon, dependent upon the magnitude of the antigenic stimulus. When viable bacteria were introduced into the LRT, systemic (as well as local) CMI was usually evoked. For example, aerosolization of $L$. monocytogenes into the LRT is followed by extensive infection and the appearance of both respiratory tract and systemic delayed hypersensitivity. This is probably the result of local bacterial multiplication followed by dissemination of intact organisms and/or bacterial antigen. On the other hand, as noted in previous studies, introduction of virulent pneumococci (without mucin) into the LRT may be followed by systemic spread of the organism but little parenchymal pulmonary disease (e.g., 34). This type of infection was followed by systemic but not LRT delayed hypersensitivity. When pneumococci and mucin were inoculated into the tracheobronchial tree, typical pneumococcal pneumonia occurred and was sometimes associated with both local and systemic CMI.

Intravenous administration of $L$. monocytogenes led to systemic infection and systemic CMI. However, LRT delayed hypersensitivity developed only when the lung was obviously involved in the infectious process. After the intravenous inoculation of pneumococci, pulmonary lesions were not seen and CMI in the LRT did not develop.

The mechanism whereby LRT cells from animals infected with listeria, which exhibit inhibition of mi- 
gration in the presence of antigen, have increased migration in the absence of antigen is unknown. This may reflect the fact that many small mononuclear cells are found in the increased "free" LRT cell population of these animals. These small, young, mononuclear phagocytes may migrate more rapidly than mature, differentiated alveolar macrophages. On the other hand, it is quite possible that the infectious or immune processes induce metabolic changes in alveolar macrophages that influence their migration characteristics. Furthermore, it is of interest to determine whether this response is related specifically to listeria infection, or is a more general phenomenon. These possibilities cannot be further evaluated from the present data.

Supernates of antigen-stimulated guinea pig lymphocyte incubations were reported to produce inhibition of peritoneal but not of alveolar macrophage migration (9). Such a finding was in conflict with other studies, which found that supernates of stimulated human, rabbit, or guinea pig lymphocyte cultures were inhibitory to alveolar macrophage migration (e.g., 4, 35, 36). The present study demonstrates that an inhibitory substance is produced by antigen-stimulated LRT and lymph node lymphocytes from animals with respiratory tract $L$. monocytogenes infection. The migration of purified alveolar macrophages from infected animals is not inhibited in the presence of antigen, excluding the possibility that cytophilic antibody plus antigen is the mechanism for migration inhibition in our model (37). The inhibitory substance in lymph node lymphocyte supernates eluted from Sephadex G-75 in a nonimmunoglobulin-containing fraction corresponding to a mol wt of approximately 65,000 (with possible lesser inhibitory activity in the $>25,000-45,000 \mathrm{~mol}$ wt range). This observation excluded the possibility that inhibition was due to the presence of antigen-antibody complexes (38). Our determination of rabbit MIF mol wt is similar to that described for guinea pig MIF by other investigators $(24,39)$. However, Remold, Katz, Haber, and David reported that peak activity of guinea pig MIF was in the $35,000-55,000$ mol wt range, with less activity in the $55,000-70,000 \mathrm{~mol}$ wt range (17). The activity of rabbit MIF (like guinea pig MIF) was abolished by incubation with insoluble chymotrypsin or neuraminidase, indicating its glycoprotein nature (18). Thus, antigen-induced rabbit MIF is similar to the previously described guinea pig counterpart and is capable of inhibiting alveolar macrophage migration.

The observation that maximum migration inhibition in the direct assays employing LRT cells from sensitized animals is delayed until approximately $48 \mathrm{~h}$ merits discussion. This finding is consistent with another recent publication (40), but differs from earlier investigations utilizing guinea pig peritoneal exudate cells, which noted that inhibition was maximal at 18-24 $\mathrm{h}$ and subsequently decreased (e.g., 14). It is likely that these differences are technical in nature, but at present they must be considered unexplained. It has been suggested that early migration of cells from the capillary tube in direct assays (employing mixtures of lymphocytes and macrophages) is independent of MIF (40). In part this delay might reflect the lag time required for sensitized lymphocytes to respond to antigen with production and/or release of MIF. This concept is supported by our documentation that there is little difference between alveolar macrophage migration inhibition at $24 \mathrm{~h}$ and at $48 \mathrm{~h}$ in indirect assays (utilizing preformed MIF).

Additional work is required to delineate the role of local or systemic CMI in recovery from or protection against respiratory tract bacterial infection. As we have already noted, CMI is known to be the major mechanism of protection against systemic L. monocytogenes infection. Protection against respiratory tract challenge with listeria was documented after systemic infection (immunization), and appeared to be related to arrival in the lungs of mononuclear phagocytes from the circulation (41). The possible protective role of local CMI after listeria respiratory tract infection (immunization) is currently being evaluated.

There is little to suggest that CMI is important in protection against pneumococcal infection. Nontypespecific immunity against systemic pneumococcal infection has been reported to follow immunization of mice with ribosomal preparations containing both RNA and protein (42). The mechanism of this protection was not clearly established. In similar systems, using other organisms, protection was thought to depend upon CMI (43). In another study, L. monocytogenes infection in mice increased their resistance to pneumococcal infection (44). Protection was not related to humoral antibody, and it was suggested that macrophage activation was the important mechanism. The possibility that CMI, involving alveolar macrophages, may play a role in protection of the LRT against reinfection with $D$. pneumoniae deserves further study.

The present investigation demonstrates that local delayed hypersensitivity occurs in the LRT after bacterial infection. The precise relationship of this immune response to LRT antibacterial activity remains to be elucidated. Recent reports indicate that stimulated lymphocyte supernates (containing MIF) or fractionated MIF (possibly in combination with other lymphokines) alter macrophage function and may be the mechanism for "activation" of peritoneal macrophages (e.g., 19, 45-50). Since MIF is now known to inhibit alveolar macrophage migration, it is important to in- 
vestigate the possibility that it mediates the activation of these phagocytes.

\section{ACKNOWLEDGMENTS}

We are indebted to Ms. Betty Bradford for secretarial assistance.

This work was supported by a Veterans Administration Clinical Investigator Award and by Veterans Administration institutional research funds. Sodium ampicillin and crystalline penicillin $\mathrm{G}$ sodium were generously supplied by Bristol Laboratories and the Upjohn Company, respectively.

\section{REFERENCES}

1. Hand, W. L., and J. R. Cantey. 1974. Antibacterial mechanisms of the lower respiratory tract. I. Immunoglobulin synthesis and secretion. J. Clin. Invest. 53: 354-362.

2. Henney, C. S., and R. H. Waldman. 1970. Cell-mediated immunity shown by lymphocytes from the respiratory tract. Science (Wash. D. C.) 169: 696-697.

3. Yamamoto, K., and R. L. Anacker. 1970. Macrophage migration inhibition studies with cells from mice vaccinated with cell walls of Mycobacterium bovis BCG: characterization of experimental system. Infect. Immun. 1: 587-594.

4. Galindo, B., and Q. N. Myrvik. 1970. Migratory response of granulomatous alveolar cells from BCG-sensitized rabbits. J. Immunol. 105: 227-237.

5. Waldman, R. H., C. S. Spencer, and J. E. Johnson, III 1972. Respiratory and systemic cellular and humoral immune responses to influenza virus vaccine administered parenterally or by nose drops. Cell. Immunol. 3: 294 300.

6. Nash, D. R., and B. Holle. 1973. Local and systemic cellular immune responses in guinea-pigs given antigen parenterally or directly into the lower respiratory tract. Clin. Exp. Immunol. 13: 573-583.

7. Jurgensen, P. F., G. N. Olsen, J. E. Johnson, III, E. W. Swenson, E. M. Ayoub, C. S. Henney, and R. H. Waldman. 1973. Immune response of the human respiratory tract. II. Cell-mediated immunity in the lower respiratory tract to tuberculin and mumps and influenza viruses. J. Infect. Dis. 128: 730-735.

8. Spencer, J. C., R. H. Waldman, and J. E. Johnson, III. 1974. Local and systemic cell-mediated immunity after immunization of guinea pigs with live or killed $M$. tuberculosis by various routes. J. Immunol. 112: 13221328.

9. Leu, R. W., A. L. W. F. Eddleston, J. W. Hadden, and R. A. Good. 1972. Mechanism of action of migration inhibitory factor (MIF). I. Evidence for a receptor for MIF present on the peritoneal macrophage but not on the alveolar macrophage. J. Exp. Med. 136: 589-603.

10. Lowry, O. H., N. J. Rosebrough, A. L. Farr, and R. J. Randall. 1951. Protein measurement with the Folin phenol reagent. J. Biol. Chem. 193: 265-275.

11. Kabat, E. A. 1961. Pneumococcal and other type-specific polysaccharides. In Experimental Immunochemistry. E. A. Kabat and M. M. Mayer, editors. Charles C Thomas, Publisher, Springfield, I1l. 2nd edition. 838-850.

12. Myrvik, Q. N., E. S. Leake, and B. Fariss. 1961. Studies on pulmonary alveolar macrophages from the normal rabbit: a technique to procure them in a high state of purity. J. Immunol. 86: 128-132.
13. David, J. R., S. Al-Askari, H. S. Lawrence, and L. Thomas. 1964. Delayed hypersensitivity in vitro. I. The specificity of inhibition of cell migration by antigens. J. Immunol. 93 : 264-273.

14. David. J. R., and R. David. 1971. Assay for inhibition of macrophage migration. In In Vitro Methods in CellMediated Immunity. B. R. Bloom and P. R. Glade, editors. Academic Press, Inc., New York. 249-258.

15. Rocklin, R. E., O. L. Meyers, and J. R. David. 1970. An in vitro assay for cellular hypersensitivity in man. J. Immunol. 104: 95-102.

16. Bloom, B. R., and B. Bennett. 1971. The assay of inhibition of macrophage migration and the production of migration inhibitory factor (MIF) and skin reactive factor (SRF) in the guinea pig. In In Vitro Methods in Cell-Mediated Immunity. B. R. Bloom and P. R. Glade, editors. Academic Press, Inc., New York. 235248.

17. Remold, H. G., A. B. Katz, E. Haber, and J. R. David. 1970. Studies on migration inhibitory factor (MIF): recovery of MIF activity after purification by gel filtration and disc electrophoresis. Cell. Immunol. 1 : 133-145.

18. Remold, H. G., and J. R. David. 1971. Further studies on migration inhibitory factor (MIF) : evidence for its glycoprotein nature. J. Immunol. 107: 1090-1098.

19. Nathan, C. F., H. G. Remold, and J. R. David. 1973. Characterization of a lymphocyte factor which alters macrophage function. J. Exp. Med. 137: 275-290.

20. David, J. R. 1973. Lymphocyte mediators and cellular hypersensitivity. N. Engl. J. Med. 288: 143-149.

21. George, M., and J. H. Vaughan. 1962. In vitro cell migration as a model for delayed hypersensitivity. Proc. Soc. Exp. Biol. Med. 111: 514-521.

22. Bloom, B. R., and B. Bennett. 1966. Mechanism of a reaction in vitro associated with delayed-type hypersensitivity. Science (Wash. D. C.). 153: 80-82.

23. David, J. R. 1966. Delayed hypersensitivity in vitro: its mediation by cell-free substances formed by lymphoid cell-antigen interaction. Proc. Natl. Acad. Sci. U. S. A. 56: 72-77.

24. Bennett, B., and B. R. Bloom. 1968. Reactions in vivo and in vitro produced by a soluble substance associated with delayed-type hypersensitivity. Proc. Natl. Acad. Sci. U. S. A. 59: 756-762.

25. Thor, D. E., R. E. Jureziz, S. R. Veach, E. Miller, and S. Dray. 1968. Cell migration inhibition factor released by antigen from human peripheral lymphocytes. Nature (Lond.). 219: 755-757.

26. Mackaness, G. B. 1969. The influence of immunologically committed lymphoid cells on macrophage activity in vivo. J. Exp. Med. 129: 973-992.

27. Lane, F. C., and E. R. Unanue. 1972. Requirement of thymus (T) lymphocytes for resistance to listeriosis. J. Exp. Med. 135: 1104-1112.

28. North, R. J. 1973. Cellular mediators of anti-Listeria immunity as an enlarged population of short-lived, replicating T cells. J. Exp. Med. 138: 342-355.

29. Wood, W. B., Jr. 1951. Studies on the cellular immunology of acute bacterial infections. Harvey Lect. 47 : 72-98.

30. Tillett, W. S., and T. Francis, Jr. 1929. Cutaneous reactions to the polysaccharides and proteins of pneumococcus in lobar pneumonia. J. Exp. Med. 59: 687-703.

31. Tremaine, M. M. 1963. Study of delayed-type sensitization to pneumococcal polysaccharides. Fed. Proc. 22: 617. (Abstr.) 
32. Biberfeld, G. 1973. Macrophage migration inhibition in response to experimental Mycoplasma pneumoniae infection in the hamster. J. Immunol. 110: 1146-1150.

33. Wetherbee, R. E. 1973. Induction of systemic delayed hypersensitivity during experimental viral infection of the respiratory tract with a myxovirus or paramyxovirus. J. Immunol. 111: 157-163.

34. Nungester, W. J., and L. F. Jourdonais. 1936. Mucin as an aid in the experimental production of lobar pneumonia. J. Infect. Dis. 59: 258-265.

35. Bartfeld, H., and T. Atoynatan. 1971. $N$-acetylcysteine inactivates migration inhibitory factor and delayed hypersensitivity reactions. Nat. New Biol. 231: 157-159.

36. Warr, G. A., and R. R. Martin. 1973. In vitro migration of human alveolar macrophages: effects of cigarette smoking. Infect. Immun. 8: 222-227.

37. Heise, E. R., S. Han, and R. S. Weiser. 1968. In vitro studies on the mechanism of macrophage migration inhibition in tuberculin sensitivity. J. Immunol. 101: 1004 1015.

38. Spitler, L., H. Huber, and H. H. Fudenberg. 1969. Inhibition of capillary migration by antigen-antibody complexes. J. Immunol. 102: 404-411.

39. Dumonde, D. C., D. A. Page, M. Matthew, and R. A. Wolstencroft. 1972. Role of lymphocyte activation products (LAP) in cell-mediated immunity. I. Preparation and partial purification of guinea-pig LAP. Clin. Exp. Immunol. 10: 25-47.

40. Philp, J. R., J. E. Johnson, III, and J. C. Spencer. 1973. Amplification of migration inhibitory factor production during the first 48 hours of exposure to antigen. Infect. Immun. 8: 781-786.

41. Truitt, G. L., and G. B. Mackaness. 1971. Cell-mediated resistance to aerogenic infection of the lung. Am. Rev. Respir. Dis. 104: 829-843.
42. Thompson, H. C. W., and I. S. Snyder. 1971. Protection against pneumococcal infection by a ribosomal preparation. Infect. Immun. 3: 16-23.

43. Smith, R. A., and N. J. Bigley. 1972. Detection of delayed hypersensitivity in mice injected with ribonucleic acid-protein fractions of Salmonella typhimurium. Infect. Immun. 6: 384-389.

44. Musher, D. M., K. R. Ratzan, and L. Weinstein. 1970. The effect of Listeria monocytogenes on resistance to pneumococcal infection. Proc. Soc. Exp. Biol. Med. 135: $557-560$.

45. Mooney, J. J., and B. H. Waksman. 1970. Activation of normal rabbit macrophage monolayers by supernatants of antigen-stimulated lymphocytes. J. Immunol. 105: 1138-1145.

46. Nathan, C. F., M. L. Karnovsky, and J. R. David. 1971. Alterations of macrophage functions by mediators from lymphocytes. J. Exp. Med. 133: 1356-1376.

47. Godal, T., R. J. W. Rees, and J. O. Lamvik. 1971. Lymphocyte-mediated modification of blood-derived macrophage function in vitro ; inhibition of growth of intracellular mycobacteria with lymphokines. Clin. Exp. Immunol. 8: 625-637.

48. Krahenbuhl, J. L., and J. S. Remington. 1971. In vitro induction of nonspecific resistance in macrophages by specifically sensitized lymphocytes. Infect. Immun. 4: 337-343.

49. Patterson, R. J., and G. P. Youmans. 1970. Demonstration in tissue culture of lymphocyte-mediated immunity to tuberculosis. Infect. Immun. 1: 600-603.

50. Fowles, R. E., I. M. Fajardo, J. L. Leibowitch, and J. R. David. 1973. The enhancement of macrophage bacteriostasis by products of activated lymphocytes. $J$. Exp. Med. 138: 952-964. 